Lepr. Rev. (1970) 41, 9-13

\title{
Results of the Leprosy Programme in Japan in the Past 60 Years*
}

\author{
YOSHIO YOSHIE \\ Director, National Institute for Leprosy Research, Tokyo, Japan
}

\section{INTRODUCTION}

The National Leprosy Control Programme in its proper sense dates back to 1907, when the Leprosy Prevention Law was enacted in Japan. This law was subsequently amended in 1931 and again in 1953 and has since been in force as amended. Because of advancements made in the treatment of leprosy, new provisions were added by the 1953 amendment to facilitate social rehabilitation of cured patients through education and occupational training.

As implementation of the National Leprosy Control Programme required leprosaria for the admission and treatment of patients, 5 national leprosaria were built in 1909, while 6 more were built in later years, bringing the total number of beds available to 13,020 in 30 years. As a result, the majority of Japanese leprosy patients were admitted to and treated at these national leprosaria. However, until the Japanese Government began to undertake campaigns against leprosy, relief work was mostly in the hands of religious groups composed of foreign missionaries. For this reason, the missionaries may well be considered the pioneers in the relief of leprosy in Japan.

Meanwhile, it was the benevolent acts of the Imperial Household, especially those of the Dowager Empress, which served as the propelling force of anti-leprosy campaigns in Japan. The Imperial Household, as well as other organizations, made frequent charitable contributions to aid the campaigns.

As a rule, all those who are suspected of spreading leprosy bacilli are encouraged to be

*Received for publication 4 August, 1969. hospitalized in leprosaria. However, when clinical symptoms of leprosy disappear and the patient is adjudged free from any danger of disseminating the bacilli as a result of treatment given in the leprosarium, he is discharged.

The number of leprosy cases in Japan has gradually decreased as a result of this segregation policy enforced in the past 60 years, and today the number has been reduced to about one-third of what it was 60 years ago. While 30,359 cases of leprosy were found under the National Leprosy Survey made in 1900, the number had decreased to 10,402 by 1966 . And the rate of incidence per 10,000 has been decreased from 6.9 in 1900 to 1.0 in 1966.

The number of leprosy patients hospitalized for treatment gradually increased as more leprosaria were established, and, as shown in Table 1, more than $93 \%$ of the total number of cases, 10,220, had been hospitalized by the end of 1967.

TABLE 1

Total number of patients and the number hospitalized

Year of No. of patients No. of patients Prevalence rate survey registered hospitalized (\%) per 10,000 population

\begin{tabular}{llrrl}
\hline 1919 & 16,216 & 1559 & $(9.1)$ & 2.92 \\
1925 & 15,351 & 2225 & $(14.5)$ & 2.57 \\
1930 & 14,263 & 3272 & $(22.2)$ & 2.21 \\
1935 & 15,193 & 5265 & $(32.0)$ & 2.19 \\
1940 & 15,763 & 9190 & $(58.3)$ & 2.16 \\
1950 & 11,094 & 8325 & $(75.0)$ & 1.3 \\
1955 & 12,169 & 11,057 & $(90.9)$ & 1.3 \\
1960 & 11,587 & $10,645(91.9)$ & 1.2 \\
1965 & 10,607 & 9874 & $(93.1)$ & 1.0 \\
1967 & 10,220 & 9537 & $(93.3)$ & 1.0 \\
\hline
\end{tabular}




\section{NEWLY DISCOVERED CASES}

The number of newly discovered cases has markedly decreased in the past 60 years. For instance, cases newly discovered in the 22 years

TABLE :2

Decrease in the number of newly discovered cases

\begin{tabular}{ccc}
\hline Year & $\begin{array}{c}\text { No. of patients } \\
\text { newly discovered }\end{array}$ & $\begin{array}{c}\text { Ratio per } 100,000 \\
\text { population }\end{array}$ \\
\hline 1947 & 607 & 0.8 \\
1948 & 712 & 0.9 \\
1949 & 778 & 1.0 \\
1950 & 604 & 0.7 \\
1951 & 487 & 0.6 \\
1952 & 326 & 0.4 \\
1953 & 315 & 0.4 \\
1954 & 333 & 0.4 \\
1955 & 331 & 0.4 \\
1956 & 283 & 0.3 \\
1957 & 361 & 0.4 \\
1958 & 362 & 0.4 \\
1959 & 295 & 0.3 \\
1960 & 257 & 0.3 \\
1961 & 235 & 0.2 \\
1962 & 211 & 0.2 \\
1963 & 175 & 0.2 \\
1964 & 135 & 0.1 \\
1965 & 125 & 0.1 \\
1966 & 106 & 0.1 \\
1967 & 116 & 0.1 \\
1968 & 87 & 0.1 \\
\hline
\end{tabular}

between 1947 and 1966 have fallen from 607 in 1947 to 87 in 1968, as shown in Table 2. Also comparison of a yearly average of 6:37.6 cases discovered in the 5-year period 1947-51 with the yearly average of 113.8 cases discovered in the 5-year period 1964-68 shows that the number has been reduced to between one-fifth and one-sixth that of the original value.

\section{SHIFT IN AGE GROUPS IN THE ONSET OF LEPROSY}

The age group 10 to 19 years exceeded all other groups in the number of new cases admitted to national leprosaria during the period 19:35-57, as shown in Fig. 1. However, the highest figure of $47 \%$ for 1935 had dropped to $35 \%$ in 1957 , and the rate of onset had shifted to higher age groups. In particular, reduction in the rate of onset in the age group 0 to 9 years was conspicuous, as the rate of $15 \%$ in 1935 had fallen to only $6 \%$ in 1957 .

Incidentally, comparison of the average value (percentage) of the number of new cases of leprosy by age groups between 1964 and 1968 with the 2 onset groups mentioned above shows not only a marked decrease in new cases but also complete elimination of the peak for the age group 10 to 19 years, which had

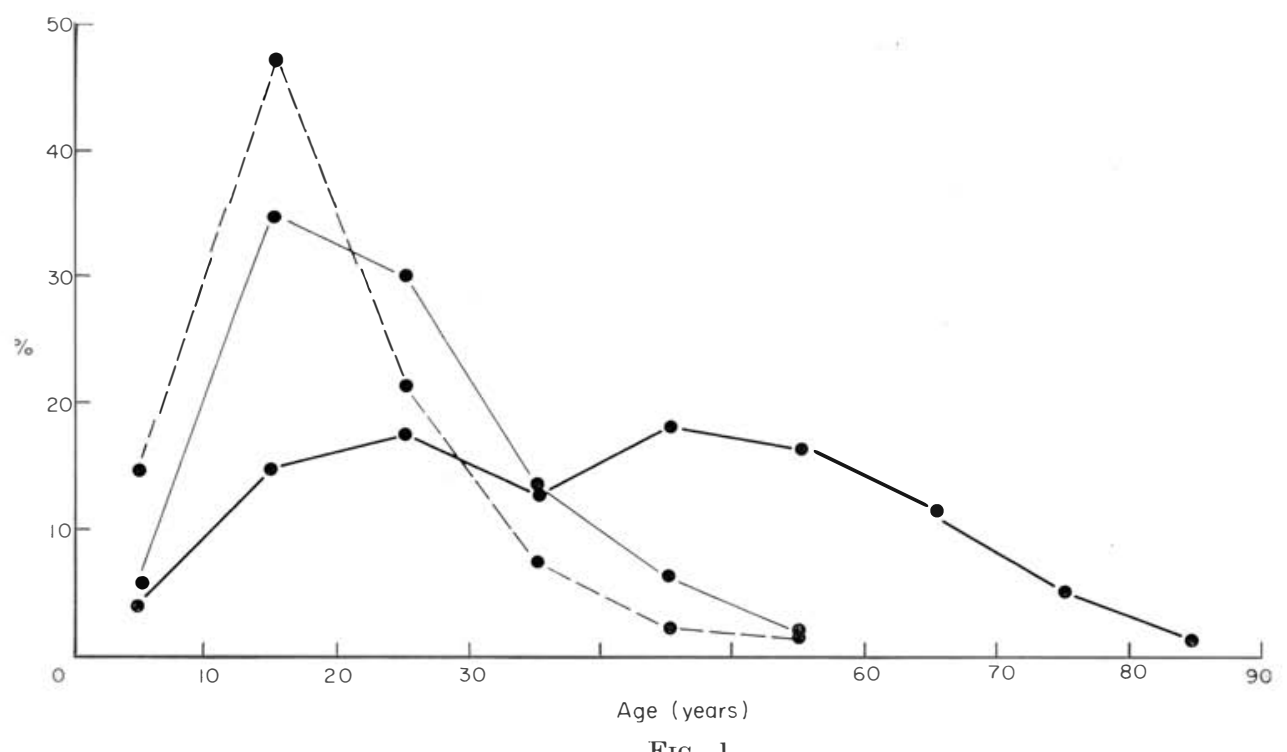

FIG. 1

Shift in the age group of the onset of leprosy; $\ldots, 1935 ; \ldots, 1957 ; \ldots, 1964-68$ (average value). 
previously shown the largest number of new cases, and a tendency towards increased onset in those of higher age groups, particularly among those aged 40 to 49 years.

\section{RATIO OF MALES TO FEMALES}

In Japan, also, the number of male patients has always been larger than that of females. This difference, however, has gradually become smaller, and the ratio of 3.3: 1 in 1905 had been reduced to $2.54: 1$ in 1920 , to $2.22: 1$ in 1940 , to $1.75: 1$ in 1957 , and to $1.66: 1$ in 1967.

\section{TYPE OF DISEASE}

When the patients admitted in the past 50 years are classified into those with the lepromatous type and non-lepromatous type of disease, the lepromatous type accounted for 70 to $75 \%$ of the total, though it has depended on the year examined. In recent years, however, no significant change in the ratio of the 2 types suggestive of any reduction in the lepromatous type has been seen.

\section{SHIFT IN THE AGE DISTRIBUTION}

As approximately $93 \%$ of leprosy patients are hospitalized in Japan, the Tama Zenshoen, one of the oldest national leprosaria in the country, was taken as a fair example of the age dis-

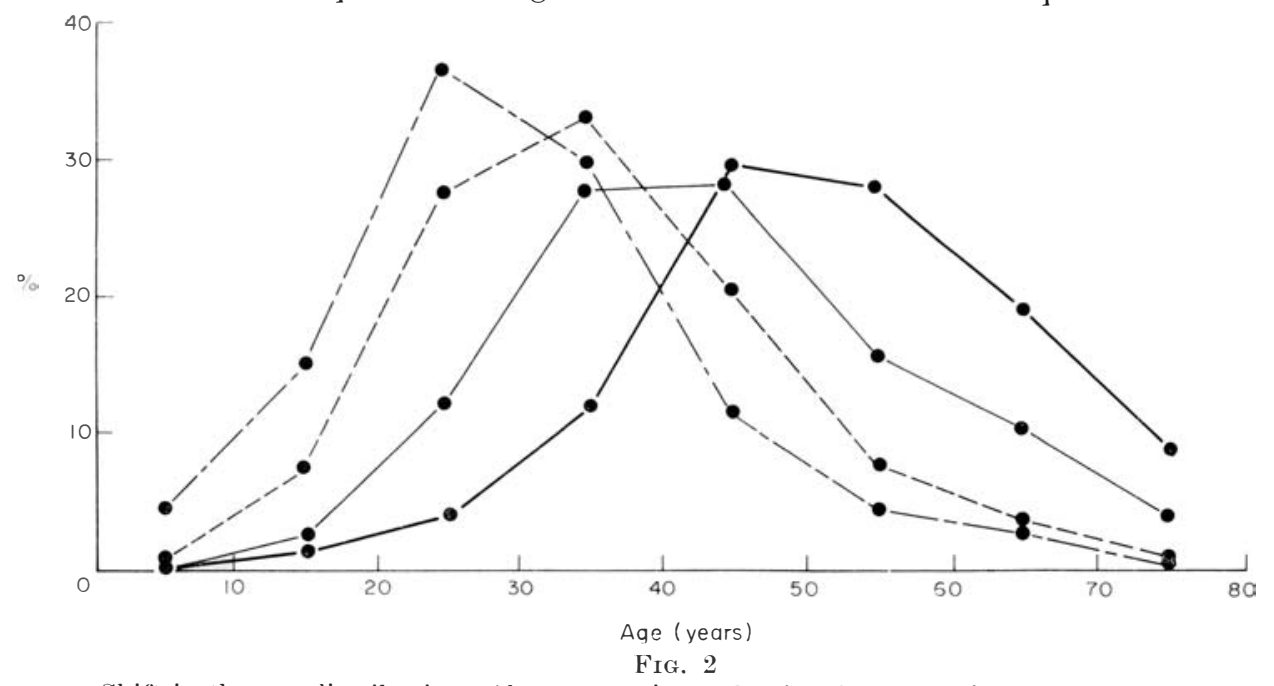

Shift in the age distribution of leprosy patients (National Leprosarium Tama Zenshoen), tribution, at 10 to 20 year intervals, of the patients admitted there between 1914 and 1968 . As shown in Fig. 2, the age distribution of Japanese leprosy patients is shifting to higher age groups. The age group 21 to 30 years occupied the highest percentage in 1914, but this had shifted to the 30 to 40 age group in 1934, and in 1958 and 1968 a shift to still higher age groups was evident.

This shift to higher age groups is considered to be due to the decrease in the number of new cases of leprosy among the younger generation as well as to the remarkable reduction in the death rate ascribable to such diseases as pulmonary tuberculosis, nephritis, and others. On the other hand, geriatric changes such as cerebral haemorrhage, circulatory disturbances, and cancer, have become the main causes of death concomitant with the advancement in age of the hospitalized patients.

\section{PATIENTS WITH ARRESTED DISEASE}

The number of patients whose leprosy has become quiescent and who, having been adjudged free from recurrence as a result of admission to and treatment in leprosaria, have been discharged, is increasing annually as shown in Table 3. The criteria for diagnosing arrested disease as employed at the Japanese leprosaria are as follows: The lepromatous lesion must be 
TABLE 3

Increase in the number of the arrested patients discharged

\begin{tabular}{cc}
\hline Year & $\begin{array}{c}\text { No. of arrested } \\
\text { patients discharged }\end{array}$ \\
1953 & 49 \\
1954 & 80 \\
1955 & 79 \\
1956 & 72 \\
1957 & 86 \\
1958 & 108 \\
1959 & 163 \\
1960 & 216 \\
1961 & 166 \\
1962 & 134 \\
1963 & 125 \\
1964 & 119 \\
1965 & 91 \\
1966 & 117 \\
1967 & 117
\end{tabular}

completely absorbed and no leprosy bacilli must be present in smears taken from different parts of the skin and from nasal mucosa. Also, neither leprosy bacilli nor active cell infiltration should be evident in biopsy specimens taken from suspicious areas of the skin. When the above state has continued for more than 2 years without any charge, ophthalmological and rhino-laryrgological examinations are carried out, and any patient passing these examinations successfully is entered on the list of arrested cases.

After discharge, DDS is, as a rule, continuously given for more than 2 years. A discharged patient visits the leprosarium every 3 months for consultation and is given sufficient DDS tablets for the following 3 months.

\section{REHABILITATION}

Most discharged patients fortunately suffer no advanced physical damage and are capable of supporting themselves by pursuing their own occupations with the help of their relatives or friends. The Japanese Leprosy Foundation also extends a helping hand to them in the recommendation of jobs and in other ways.

On the other hand, there are many disabled patients in Japanese leprosaria. In fact, such patients account for nearly $80 \%$ of all the hospitalized cases. Patients with curable stigmata or deformities are treated by plastic surgery and receive physiotherapy as well as job-training to prepare them for future social rehabilitation. The problem, however, is how blind patients with arrested disease and those with advanced physical handicaps difficult to treat should be cared for in the future. This question, in fact, constitutes a serious problem for the Japanese Government and leprosaria.

\section{CONCLUSIONS}

The National Leprosy Control Programme of Japan has now been in force for 60 years and during this time the number of patients has gradually decreased until today it is reduced to one-third of the former total. In particular, the number of new cases of leprosy has shown a marked decrease in the past 20 years (to onefifth or sixth). On the other hand, leprosaria are burdened with an increasing number of seriously disabled patients as well as those who have lost the desire to rehabilitate themselves and try to remain in hospital permanently. Although the treatment of such patients poses serious problems, it can truly be said that Japan's leprosy control programme has achieved positive results.

In all, 11 national leprosaria have been established in the 60 years since 1907 , and when private facilities are included, the total number of beds available has reached 13,300 or more. Patients with active leprosy who represent a danger by spreading bacilli are segregated in these leprosaria, and as a result of treatment the number of sufferers capable of infecting others is gradually decreasing in society at large. This is considered to have rapidly reduced the chances of leprosy spreading among close contacts, particularly among children of the patients' households.

The tendency towards a rapid decrease in new cases of leprosy in Japan, however, cannot be considered to arise solely from the segregation policy followed; the improvement in national living conditions after World War II and the 
spread of up-to-date knowledge of sanitation and public health must also be considered as being important contributory causes.

Incidentally, it is hoped that the question of a possible relationship between BCG vaccination, which since 1948 is now given to all persons with a negative tuberculin reaction from the time they are babies, and the effect of the reduced number of new leprosy cases will be investigated in detail.

\section{ACKNOWLEDGEMENTS}

I wish to express my appreciation of the advice and aid provided by Dr. S. Hazama of the National Leprosarium, Tama Zenshoen.

\section{REFERENCES}

HAYASh, y. (1960). La Lepro, 29, No. 2.

Ministry of Health and Welfare, Japan. Statistics on leprosy patients (1940).

TAKIKAWA, K. (1959). Igaku Kenkyu (Fukuoka), 29, 3. TOFU-KYOKA (Japanese Leprosy Foundation). (1968). Leprosy in .Japan. 